\title{
Acute $\beta$-Amyloid Administration Disrupts the Cholinergic Control of Dopamine Release in the Nucleus Accumbens
}

\author{
Stefania Preda', Stefano Govoni*,', Cristina Lanni', Marco Racchi', Elisa Mura', Massimo Grilli ${ }^{2}$ and \\ Mario Marchi ${ }^{2}$ \\ 'Department of Experimental and Applied Pharmacology, Centre of Excellence in Applied Biology, University of Pavia, Pavia, Italy; ${ }^{2}$ Section of \\ Pharmacology and Toxicology, Department of Experimental Medicine, University of Genoa, Genoa, Italy
}

\begin{abstract}
The clinical presentation of Alzheimer's disease is characterized by memory deficits but it also involves the impairment of several cognitive functions. Some of these cognitive and executive functions are mediated by limbic areas and are regulated by dopaminergic neurotransmission. Furthermore, literature data suggest that $\beta$-amyloid $(\mathrm{A} \beta)$ can influence synaptic activity in absence of neurotoxicity and in particular can impair cholinergic modulation of other neurotransmitter actions. In the present study, we evaluated whether small concentrations of $A \beta$ could disrupt cholinergic control of dopamine (DA) release in nucleus accumbens using in vivo (brain dialysis) and in vitro (isolated synaptosomes) models. The cholinergic agonist carbachol (CCh) greatly enhanced DA release from dopaminergic nerve endings in nucleus accumbens both in vivo and in vitro. This effect was mainly exerted on muscarinic receptors because it was inhibited by the muscarinic antagonist atropine and it was unaffected by the nicotinic antagonist mecamylamine. Also the nicotinic agonists epibatidine and nicotine evoked a dopaminergic outflow in nucleus accumbens, which, however, was lower. A $\beta$ I-40 in absence of neurotoxicity fully inhibited the DA release evoked by $C C h$ and only marginally affected the DA release evoked by epibatidine. The PKC inhibitor GFI 09203X mimicked the effect of $A \beta$ on DA release and, in turn, A $\beta$ impaired PKC activation by CCh. We can suggest that, in nucleus accumbens, $A \beta$ disrupted in vivo and in vitro cholinergic control of DA release by acting on muscarinic transduction machinery. Neuropsychopharmacology (2008) 33, I062-1070; doi: I0.1038/sj.npp. I 30 I485; published online 20 June 2007
\end{abstract}

Keywords: Alzheimer's disease; $\beta$-amyloid; dopamine; carbachol; cholinergic receptors; nucleus accumbens

\section{INTRODUCTION}

Two series of considerations, concerning the clinical presentation of Alzheimer's disease (AD) and the putative molecular mechanisms underlying this illness, prompted us to study the effect of $\beta$ amyloid $(\mathrm{A} \beta)$ on classical neurotransmission in in vivo and in vitro experimental models.

The clinical presentation of $\mathrm{AD}$ involves the impairment of several cognitive functions including, but not limited, to memory. Thus complex symptoms of $\mathrm{AD}$ do not fit the single neurotransmitter deficit model even if there is no doubt that cholinergic transmission impairment plays an important role. Within this context some cognitive and executive functions are predominantly mediated by limbic areas that play a critical role in elaborating thoughts, behavior, and emotions using representational knowledge: operations often referred to as working memory. In

* Correspondence: Professor S Govoni, Department of Experimental and Applied Pharmacology, Centre of Excellence in Applied Biology, University of Pavia, Viale Taramelli, 14, 27100 Pavia, Italy, Tel: + 39 0382 987394, Fax: + 390382 987405, E-mail: govonis@unipv.it Received 26 January 2007; revised 14 May 2007; accepted 18 May 2007 particular, studies have suggested a direct involvement of dopamine (DA) in the regulation of different aspects of cognitive and executive functions in limbic areas. DA acts as a key neurotransmitter in the brain and shows a regulatory role for limbic functions; it acts as a powerful regulator of different aspects of cognitive brain functions. The integrative properties of the dopaminergic system are probably associated with direct contribution to cognitive functions at the cortical level, namely in working memory and executive functions. Such functions are highly vulnerable to aging (Arnsten and Li, 2005; Nieoullon, 2002; Nieoullon and Coquerel, 2003) and profoundly affected by AD (Baudic et al, 2006; Germano and Kinsella, 2005; Waltz et al, 2004). Moreover, animal studies suggest that both $\mathrm{AD}$ and ageassociated cognitive impairment reflect vulnerability of the same circuits (Hof and Morrison, 2004).

The second set of considerations concerns the recent observations made by various groups showing that $\mathrm{A} \beta$ may exert synaptic activities at levels that do not result in toxicity (Kamenetz et al, 2003; Zhong et al, 2003). Zhong et al (2003) suggested that $\mathrm{A} \beta$, in conditions not resulting in neurotoxicity, impairs cholinergic responses mediated by cholinergic muscarinic receptors by acting on the transduction machinery, in particular on PKC. This last consideration fits several observations including ours (Govoni et al, 
1993) on the impairment of the PKC transduction system in AD. Furthermore, in striatum and limbic areas, a cholinergic-DA link has been demonstrated showing that acetylcholine may promote the activation of DA terminals by regulating DA release (De Klippel et al, 1993; Giorquieff et al, 1977; Kitamura et al, 1999; Xu et al, 1989; Zhang et al, 2002). All this leads to the hypothetical scenario of an $\mathrm{A} \beta$ driven early dysfunction of cholinergic responses occurring at relatively low concentrations of soluble $\mathrm{A} \beta$, not giving origin to fibrils, that may disrupt cholinergic responses and consequently turn off DA terminals leading to an early impairment of executive functions.

This biological hypothesis is testable in animal models. In fact, it is possible to infuse $\mathrm{A} \beta$ into the brain of laboratory rodents and simultaneously monitor the extracellular release of neurotransmitters by the microdialysis technique. This was exactly our approach. Within this context we chose the nucleus accumbens as a test area because it is a region of convergence of limbic forebrain inputs and midbrain dopaminergic pathways, important for the control of various behaviors. In addition, there are studies that suggest the existence of a functional interaction among various neurotransmitters including acetylcholine and DA in this area of the brain. In particular, it has been shown that in nucleus accumbens the cholinergic receptor activation increases DA release (Kitamura et al, 1999). The choice of this brain area is further supported by the observation that in man the striatum (Brilliant et al, 1997; Mann and Iwatsubo, 1996) and in particular the ventral striatum, which includes the nucleus accumbens, is frequently affected by amyloid deposits and it is particularly vulnerable to AD (Suenaga et al, 1990). Moreover, taking advantage of previously developed (Marchi et al, 1985; Raiteri et al, 1984) in vitro models of synaptic neurotransmitter release, we investigated the direct effects of $\mathrm{A} \beta$ on isolated synaptosomes.

\section{MATERIALS AND METHODS}

\section{In Vivo Experiments}

Animals and microdialysis probe implantation. Male Wistar rats (275-300 g; Harlan, Udine Italy), housed in standard conditions (temperature $23 \pm 1{ }^{\circ} \mathrm{C}$; humidity $50 \%$ ) with 12:12 light/dark cycles, water, and food ad libitum, were anesthetized with Equithesin $3 \mathrm{ml} / \mathrm{kg}$ (pentobarbital $9.7 \mathrm{~g}$, chloral hydrate $42.5 \mathrm{~g}, \mathrm{MgSO}_{4} 21.3 \mathrm{~g}$ for $1 \mathrm{~L}, 11 \%$ ethanol, $42 \%$ propylene glycole $\mathrm{v} / \mathrm{v}$ ) administered intraperitoneally and placed in a stereotaxic apparatus (David Kopf Instruments, Tujunga, CA, USA). All experimental procedures were performed according to international regulations for the care and treatment of laboratory animals and in accordance with the Italian Act (DL n 116, GU, suppl 40, 18 February, 1992) and with EEC Council Directive (86/609, OJ L 358, 1, 12 December, 1987).

All in vivo experiments were performed using microdialysis probes, made in our laboratory according to the original method described by Di Chiara et al (1993) with cellulose (Emophan Bellco Artificial OR-internal diameter $200 \mu \mathrm{m}$, cutoff $40 \mathrm{KDa}$; Bellco, Mirandola, Italy), with a $2-\mathrm{mm}$ nominal active length. The probe was implanted in the shell of nucleus accumbens $(\mathrm{AP}+1.6 \mathrm{~mm}, \mathrm{ML} \pm 0.8 \mathrm{~mm}$ from bregma and DV $-8.0 \mathrm{~mm}$ from dura) according to the Paxinos and Watson atlas (Paxinos and Watson, 1998).

Microdialysis samples collection. Twenty-four hours after the surgical procedure, the probe was perfused with artificial cerebrospinal fluid (aCSF: $145 \mathrm{mM} \mathrm{NaCl}, 2.8 \mathrm{mM}$ $\mathrm{KCl}, 1.2 \mathrm{mM} \mathrm{CaCl}, 1.2 \mathrm{mM} \mathrm{MgCl} 2,1.4 \mathrm{mM}, \mathrm{Na}_{2} \mathrm{HPO}_{4} \mathrm{pH}$ $7.2-7.4$ ) at $2 \mu \mathrm{l} / \mathrm{min}$ using a $1000 \mu \mathrm{l}$ syringe (Hamilton) and a microinjection pump (CMA/100, CMA/Microdialysis AB). Fractions were collected every $20 \mathrm{~min}$ in $100 \mu \mathrm{l}$ Eppendorf tubes.

Chromatography. In vivo dialysate samples were analyzed for DA concentration using high-pressure liquid chromatography with electrochemical detection (ESA Coulochem II Bedford-MA) using a Supelcosil LC-18-DB Column $15 \mathrm{~cm} \times 4.6 \mathrm{~mm}$ packed with a $5-\mu \mathrm{m} \mathrm{C}_{18}$ stationary phase (Supelco) and a sample injection Rheodyne 7125 with $20 \mu \mathrm{l}$ loop. The pH 5.5 mobile phase consisted of $0.71 \mathrm{~g} \mathrm{Na}_{2} \mathrm{HPO}_{4}$, $6 \mathrm{~g} \mathrm{NaH}_{2} \mathrm{PO}_{4}, 15 \%$ methanol (v/v), $33.6 \mathrm{mg} \mathrm{Na}$ ethylenediaminetetraacetic acid (EDTA) and $116 \mathrm{mg}$ octyl sodium sulfate dissolved in a final volume of $1 \mathrm{~L}$ solution. The phase was degassed under vacuum and simultaneously filtered through a Millipore $0.2 \mu \mathrm{m}$ pore membrane and was delivered with a Waters (Millipore, Mildford, MA, USA) Model 510 pump at flow rate of $1.3 \mathrm{ml} / \mathrm{min}$. DA was detected at $2 \mathrm{nA}$ with a Model 5011 dual-electrode analytical cell. The detector was operated at a nominal potential of $+130 \mathrm{mV}$ applied to the first electrode and a potential of $-125 \mathrm{mV}$ applied to the second electrode. Only the signal generated at the second electrode was routinely recorded. The analytical cell signal was recorded on a Houston Instruments (Gistel, Belgium) Omniscribe recorder. Dialysate samples $(20 \mu \mathrm{l})$ were manually injected into the Rheodyne injector using a $50 \mu \mathrm{l}$ Hamilton syringe. The sensitivity of the assay for DA was $3 \mathrm{fmol}$ per sample.

Statistics. Values were expressed as percentage of basal values. The average concentration of four consecutive samples immediately preceding the drug dose (less than $10 \%$ variation) was considered as the basal value and was defined as $100 \%$.

For statistical analysis the GraphPad Instat statistical package (version 3.05 GraphPad software, San Diego, CA, USA) was used. The data were analyzed by analysis of variance (ANOVA) followed when significant by an appropriate post hoc comparison test. When the Bartlett's test indicated nonhomogeneity of variance a nonparametric test, that is the Kruskal-Wallis ANOVA followed by Dunn's test, was applied. The reported data are expressed as means \pm SEM.

Immunohistochemical analysis. Brain tissue samples were frozen and stored at $-80^{\circ} \mathrm{C}$. For immunodetection of infused $\mathrm{A} \beta$ peptide, $20 \mu \mathrm{m}$ coronal sections were incubated with a primary monoclonal antibody recognizing $\mathrm{A} \beta$ protein (clone 4G8; Chemicon International). Sections were then incubated with a mouse anti-IgG antibody RPE conjugated (Dako). After the fluorescent labelling procedures, sections were finally counterstained for DNA with HOECHST 33342 and mounted in a drop of Mowiol (Calbiochem, Inalco SpA, Milan, Italy). 


\section{Ex Vivo Experiments}

Western blot procedure. For detecting activated $\mathrm{PKC}$, a phospho-PKC (pan) antibody that recognizes $\mathrm{PKC} \alpha, \beta \mathrm{I}, \beta \mathrm{II}$, $\varepsilon, \eta$, and $\delta$ isoforms only when phosphorylated at a carboxyl-terminal residue homologous to Ser660 of PKC $\beta$ II was used in the Western blot analysis. At the end of $\mathrm{A} \beta$ infusion, the rats were killed and the cerebrum was extracted. Brain tissue corresponding to shell of accumbens was taken by punch and lysed by addition of ice-cold lysis buffer $(50 \mathrm{mM}$ Tris/ $\mathrm{HCl}, \mathrm{pH} 7.5,150 \mathrm{mM} \mathrm{NaCl}, 50 \mathrm{mM}$ EDTA, and $1 \%$ Triton $\mathrm{X}-100,1 \mathrm{mM} \mathrm{Na} \mathrm{VO}_{4}$ and protease inhibitors). Proteins were subjected to SDS-PAGE (10\%) and then transferred onto PVDF membrane (DuPont NEN, Boston, MA). The membrane was blocked for $1 \mathrm{~h}$ with $5 \%$ non fat dry milk in Tris-buffered saline containing $1 \%$ Tween 20. For the detection of PKC membranes were immunoblotted with the phospho-PKC (pan) antibody (Cell Signaling, $1: 1000$ ) overnight at $4{ }^{\circ} \mathrm{C}$. The detection was carried out by incubation with horseradish peroxidase conjugated goat anti-rabbit IgG (Kirkegaard and Perry Laboratories, Gaithersburgh, MD, USA) for $1 \mathrm{~h}$ as secondary antibody. The blots were then washed extensively and phospho-PKC visualized using an enhanced chemiluminescent methods (Pierce, Rockford, IL, USA). Then the blots were stripped for $30 \mathrm{~min}$ at $50^{\circ} \mathrm{C}$ followed by saturation in $5 \%$ nonfat dry milk and incubated with a PKCalpha antibody (Transduction Laboratories, $1: 1000$ ).

Densitometry and statistics. Following acquisition of the Western blot image through an AGFA scanner and analysis by means of the Image 1.47 program (Wayne Rasband, NIH, Research Services Branch, NIMH, Bethesda, MD, USA), the relative densities of the bands were analyzed as described previously (Lanni et al, 2004). Data were analyzed using the analysis of variance test followed, when significant, by the Student's $t$-test. The data reported are expressed as mean \pm SEM of at least three independent experiments.

\section{In Vitro Experiments}

Superfusion of isolated nerve endings. Crude synaptosomes were prepared as described previously and labelled with $\left[{ }^{3} \mathrm{H}\right] \mathrm{DA}\left(\left[{ }^{3} \mathrm{H}\right] \mathrm{DA}\right.$; final concentration $\left.0.05 \mu \mathrm{M}\right)$ in the presence of $0.1 \mu \mathrm{M}$ of the serotonin uptake blocker 6nitroquipazine and $0.1 \mu \mathrm{M}$ of the noradrenaline (NA) blocker nisoxetine (Marchi et al, 1985). After the labelling period, identical portions of the synaptosomal suspensions were layered on microporous filters at the bottom of parallel superfusion chambers thermostated at $37^{\circ} \mathrm{C}$ (Marchi et al, 1985; Raiteri et al, 1984).

Synaptosomes were superfused at $0.5 \mathrm{ml} / \mathrm{min}$ with standard physiological solution aerated with $95 \% \mathrm{O}_{2}$ and $5 \%$ $\mathrm{CO}_{2}$, at $37^{\circ} \mathrm{C}$.

The system was first equilibrated during $36 \mathrm{~min}$ of superfusion; subsequently, five consecutive 1-min fractions were collected. Synaptosomes were exposed to agonists at the end of the first fraction collected $(t=37 \mathrm{~min})$ till the end of the superfusion, while antagonists were added $8 \mathrm{~min}$ before the agonists.

Fractions collected and superfused synaptosomes were counted for radioactivity.

The amount of radioactivity released into each superfusate fraction was expressed as a percentage of the total synaptosomal tritium content at the start of the fraction collected (fractional efflux). Drug effects were expressed as percent increase over basal release and were evaluated as the ratio between the percentage of tritium released into the fraction where the maximal releasing effect was observed and that in the first fraction collected; this ratio was compared with the corresponding ratio obtained under control conditions (no drug added).

The high $\mathrm{K}^{+}$evoked release was monitored according to Grilli et al (2005).

Direct comparison analyses were performed with the two-tailed Student's $t$-test.

\section{RESULTS}

\section{In Vivo Experiments}

To test the effect of $\mathrm{A} \beta$ infusion on $\mathrm{DA}$ release, we first studied whether $\mathrm{A} \beta(1 \mu \mathrm{M})$ administration through the dialysis probe allowed the delivery of the peptide to the tissue. Immediately after the perfusion of the peptide, $\mathrm{A} \beta$ immunoreactivity was detected within the brain area where the dialysis probe was located. At this time the peptide showed a range of diffusion comparable to the end of the tip $(200 \mu \mathrm{M})$ (Figure 1a). Three hours after the interruption of $1 \mu \mathrm{M} \mathrm{A} \beta$ 1-40 infusion, the peptide was partially cleared from the area of interest (Figure $1 \mathrm{~b}$ ). The decreased content of $\mathrm{A} \beta$ 1-40, observed after $3 \mathrm{~h}$ from the injection of the peptide, suggested a putative clearance of the protein either
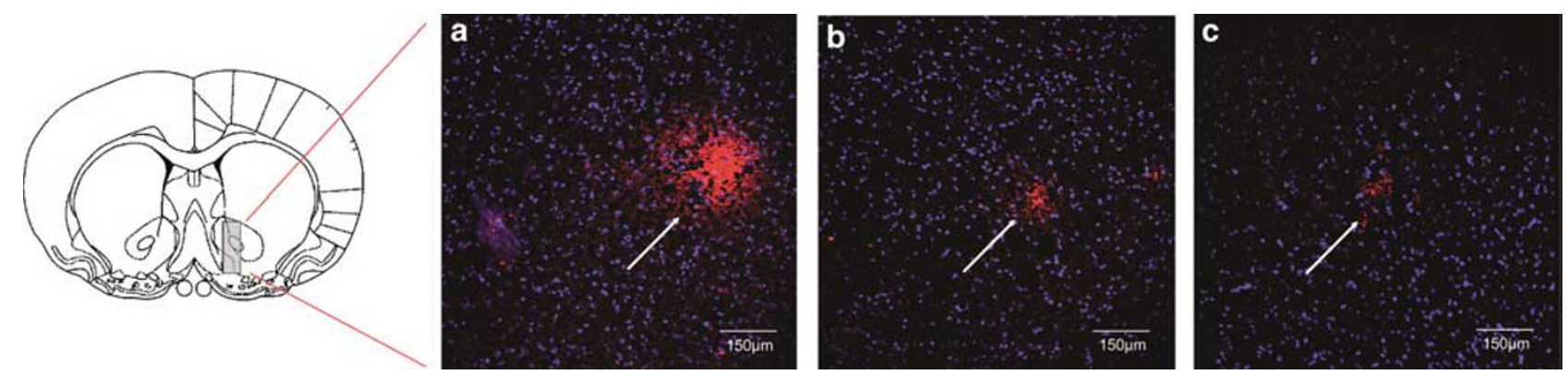

Figure I Coronal section indicating the area (nucleus accumbens) in which the dialysis probe was implanted and fluorescence micrographs showing the presence of human $\beta$-amyloid $(A \beta)$ protein. (a) $A \beta$ immunoreactivity (red-PE staining, white arrow) immediately after perfusion of I $\mu M A \beta I-40$. (b) $A \beta$ immunoreactivity $3 \mathrm{~h}$ following I $\mu \mathrm{M} A \beta \quad$ I-40 infusion. (c) $A \beta$ immunoreactivity immediately after perfusion of $10 \mu \mathrm{M} A \beta$ I-42. Nuclear DNA was counterstained with Hoechst 33342 (blue staining). Magnification: $\times 20$. 
by the cerebral tissue or by the probe. We also perfused $\mathrm{A} \beta$ 1-42. At variance with $\mathrm{A} \beta 1-40, \mathrm{~A} \beta$ 1-42 had difficulty to be delivered to the tissue. Indeed even after the administration of $10 \mu \mathrm{M} \mathrm{A} \beta 1-42$ the presence of the peptide within the nucleus accumbens of the perfused rats was at least one order of magnitude lower than that of $\mathrm{A} \beta 1-40$, as estimated from the intensity of the staining (Figure 1c). Then we designed a pilot study in which we stimulated DA release in the nucleus accumbens by infusing carbachol (CCh). Carbachol (1-200 $\mu \mathrm{M})$ elevated DA outflow in a concentration-dependent manner as shown in Figure 2a. The maximal effect (a stimulation of DA outflow up to 11 times the basal) was observed with $100 \mu \mathrm{M}$ CCh. Increasing the concentration of CCh over $100 \mu \mathrm{M}$ did not further stimulate DA outflow. A control experiment was performed to isolate presynaptic response, using the blocker of voltage-sensitive sodium channels tetrodotoxin (TTX). Therefore we coinfused through the dialysis probe $100 \mu \mathrm{M}$ CCh with $1 \mu \mathrm{M}$ TTX and we observed that TTX completely prevented the CCh-induced DA release (Figure 2a, inset).

The effect of CCh was at least partially mediated by muscarinic cholinergic receptors since it was inhibited (by $75 \%$ ) by atropine (Atr $1 \mu \mathrm{M}$ ) administration but only marginally (by $14 \%$ ) by the administration of mecamylamine $(\mathrm{Mec} 50 \mu \mathrm{M})$ (Figure $2 \mathrm{~b}$ ). The view that the effect of CCh on DA outflow was mainly mediated by muscarinic receptor activation was further supported by the observation that epibatidine (Epi, 1-125 $\mu \mathrm{M})$, a nicotinic agonist, was less effective than CCh in eliciting DA outflow from nucleus accumbens. The peak effect (4.2 times over basal) was observed with $100 \mu \mathrm{M}$ Epi and was $37 \%$ of the effect observed with CCh (Figure 2a).

The effect of Epi was reduced by Mec by $64 \%$ (Figure $2 \mathrm{~b}$ ). A $\beta$ 1-40 infusion, started $40 \mathrm{~min}$ before $\mathrm{CCh}$, greatly impaired (72\% inhibition) the ability of CCh $(100 \mu \mathrm{M})$ to stimulate DA release at peptide doses as low as $1 \mu \mathrm{M}$. The concentration-response curve $(0.1-10 \mu \mathrm{M})$ of the inhibition by $\mathrm{A} \beta$ of CCh-induced DA release was steep (Figure $2 \mathrm{c}$, inset). $\mathrm{A} \beta 1-42$ and the reverse peptide $\mathrm{A} \beta 40-1(10 \mu \mathrm{M})$ were ineffective (Figure $2 \mathrm{c}$ ). $\mathrm{A} \beta$ infusion did not inhibit the Epi-induced DA release as shown in Figure 2d. None of the tested concentrations of $\mathrm{A} \beta$ affected the basal level of extracellular DA in nucleus accumbens at any of the time points considered (from 20 min up to $6 \mathrm{~h}$ of infusion) (not shown).

To test the persistence of $A \beta$ effect, we first examined the response to repeated CCh administrations. The effect of a single dose of CCh was maximal within the time frame of sample collection $(20 \mathrm{~min})$ and returned to prestimulus values $20 \mathrm{~min}$ after the infusion was stopped. Repeated administrations of CCh had the same effect on DA release (Figure 3a), indicating the absence of tachyphylaxis.

The effect of $\mathrm{A} \beta$ on CCh-elicited DA release persisted continuing the $\mathrm{A} \beta$ infusion as shown by the fact that a second and third stimulation with $100 \mu \mathrm{M}$ CCh were ineffective, indicating that there was no tolerance to $\mathrm{A} \beta$

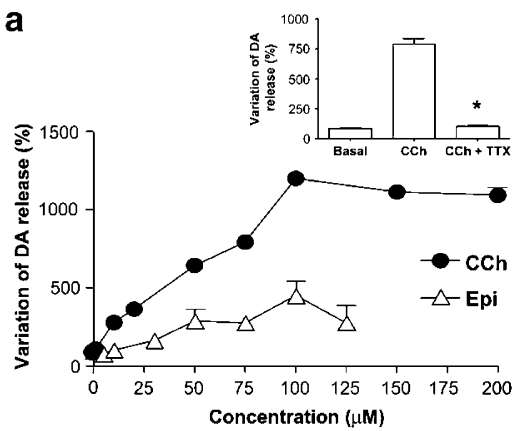

c

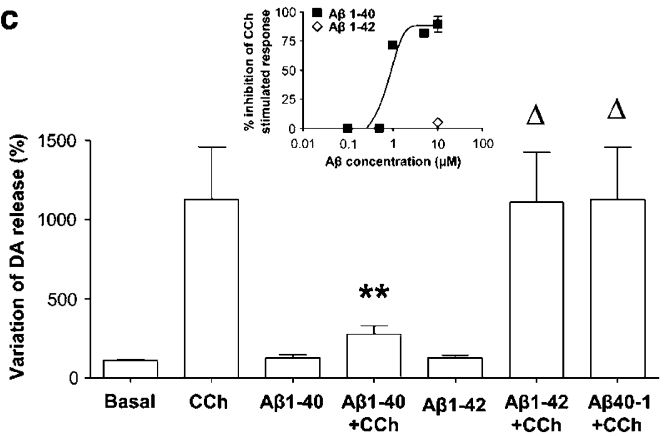

b

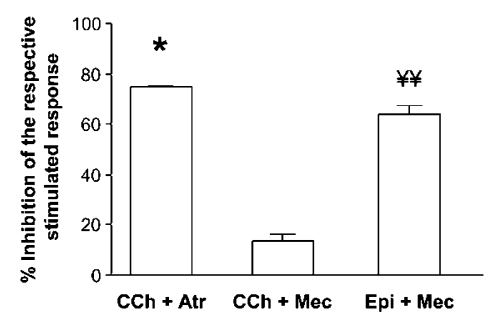

d

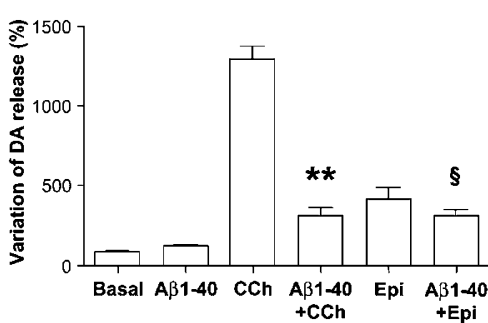

Figure $2 \beta$-amyloid $(A \beta)$ infusion inhibits carbachol-elicited DA outflow from nucleus accumbens by acting on cholinergic muscarinic receptors. (a) Carbachol (CCh) or epibatidine (Epi) were infused at various concentrations as indicated in the figure. Each sample was collected for $20 \mathrm{~min}$ in the presence of the respective carbachol concentration. The inset shows the effect of the coinfusion of I $\mu$ M tetrodotoxin (TTX) with I00 $\mu$ M CCh on DA release. *P $<0.05$ (Dunn's test) compared to CCh. (b) Effect of a maximally effective CCh ( $100 \mu \mathrm{M})$ or Epi ( $100 \mu \mathrm{M})$ concentration on DA outflow and inhibition by atropine (Atr) $\left(\mathrm{I} \mu \mathrm{M}\right.$ ) or mecamylamine (Mec) $50 \mu \mathrm{M}$ coinfused with CCh or Epi. *P $<0.05$ vs CCh; ${ }^{¥} P=0.00$ I vs Epi (Dunn's test). (c) Effect of the A $\beta$ I -40 (I $\mu \mathrm{M}$ ), A $\beta$ I -42 $(I 0 \mu M)$, and the reverse peptide $A \beta 40-1(10 \mu M)$ on the CCh stimulated DA release. ${ }^{*} * P<0.0 I$ vs $C C h ;{ }^{\Delta} P>0.05$ vs CCh (Dunn's test). Inset: the effect of various concentration of $A \beta(0.1-10 \mu \mathrm{M})$ and, for comparison, of $A \beta I-42(10 \mu \mathrm{M})$ on the CCh-stimulated DA release. (d) Effect of $A \beta($ I $\mu \mathrm{M})$ on Epi (I00 $\mu \mathrm{M})$ stimulated DA release. The effect of $A \beta$ on $C C h(100 \mu \mathrm{M})$ was repeated for control in this set of experiments. ${ }^{*} * P<0.0$ I vs $C C h ;{ }^{\circledR} P>0.05$ vs Epi (Dunn's test). Data are expressed as mean \pm SEM of 5-8 individual rats for each experimental group in each panel. 
a

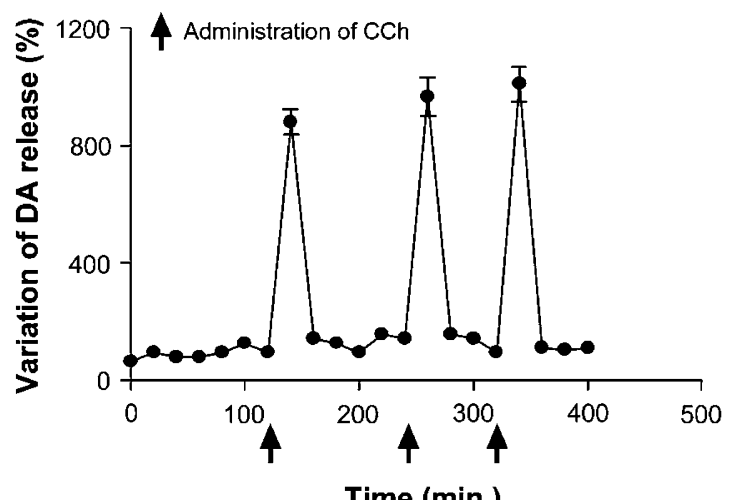

b

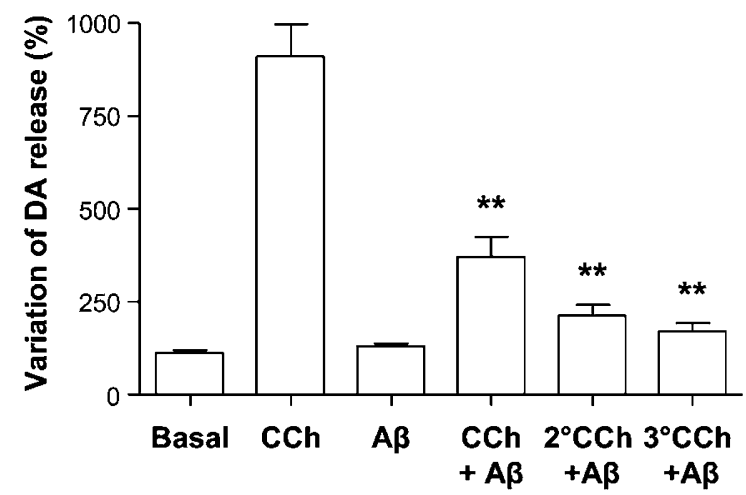

c

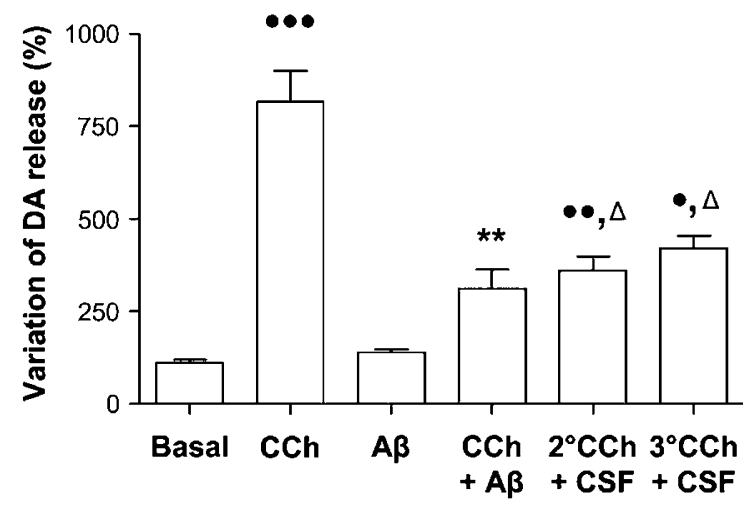

Figure 3 Effect of $\beta$-amyloid $(A \beta)$ on carbachol-induced dopamine (DA) release after continuous infusion and after stopping the treatment. (a) Time of onset and offset of the action of carbachol (CCh) and the effect of repeated CCh administrations. The arrows indicate the time of CCh administration which ended after 20 min. (b) Effect of the continuous infusion of $A \beta \mid-40$ on repeated CCh stimuli. (c) Effect of repeated CCh stimuli on DA release after ending the $A \beta \mid-40$ infusion. ** $P<0.0$ I vs $C C h$; $\bullet P<0.05$ vs basal; $\bullet \bullet P<0.0$ I vs basal; $\bullet \bullet \bullet P<0.00$ I vs basal; ${ }^{\Delta} P>0.05$ vs CCh (Dunn's test). Data are expressed as mean \pm SEM of 5-8 individual rats for each experimental group in each panel.

inhibition (Figure $3 \mathrm{~b}$ ). The action of $\mathrm{A} \beta$, however, was reversible as shown by the fact that after discontinuing the infusion of $\mathrm{A} \beta$ a second and third stimulation with $100 \mu \mathrm{M}$ CCh led to a significant increase of DA outflow over basal even if the mean values were lower than those observed with $\mathrm{CCh}$ before $\mathrm{A} \beta$ infusion (Figure $3 \mathrm{c}$ ). The administration of GF 109203X $(25 \mu \mathrm{M}, 100 \mathrm{~min})$, a protein kinase $\mathrm{C}$ inhibitor, inhibited the effect of CCh on DA release to an extent (72\%) similar to that observed by blocking muscarinic receptors or by infusing $\mathrm{A} \beta(1 \mu \mathrm{M})$ (Figure $4 \mathrm{a})$.

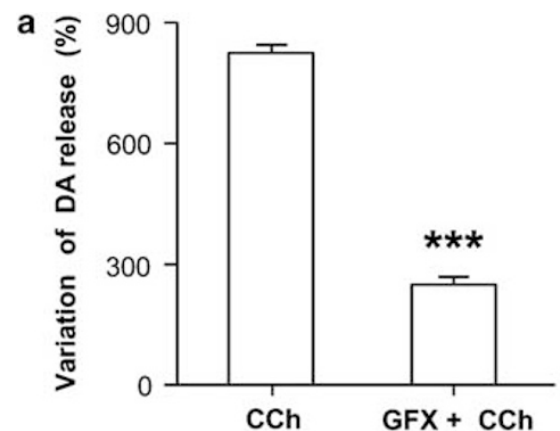

b
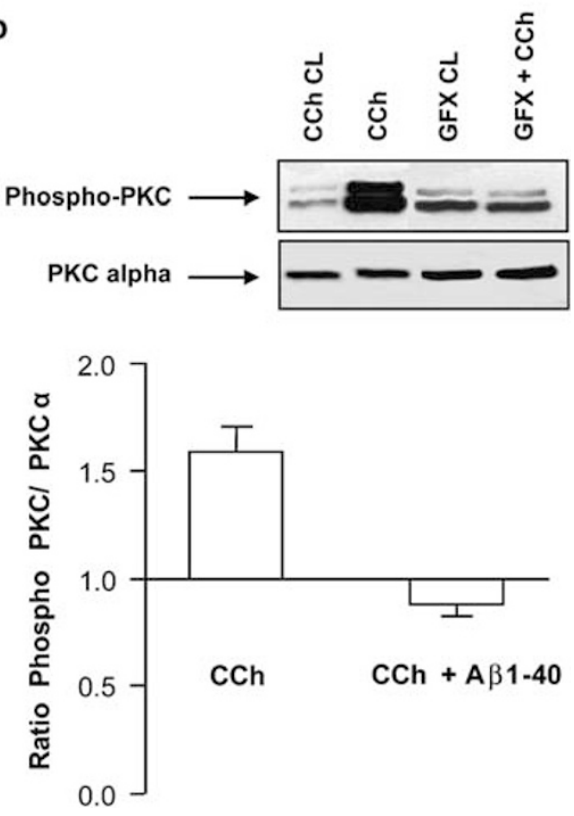

Figure 4 Protein kinase $C(P K C)$ inhibition prevents the carbacholelicited dopamine (DA) outflow from nucleus accumbens and $\beta$-amyloid $(A \beta)$ impairs PKC activation by carbachol (CCh). (a) Inhibition of CCh effect on DA release by pretreatment with the PKC inhibitor GFI 09203X $(25 \mu \mathrm{M})$. **** $P<0.0001$ vs $C C h$ (since the variance was homogeneous, a two-tailed Student's t-test was used to evaluate the significance of the difference). (b) Phospho PKC/PKC $\alpha$ ratio following PKC activation by $C C h$ and inhibition by $A \beta \quad 1-40$. CL: control side. Data are expressed as mean \pm SEM of 5-7 individual rats for each experimental group in each panel.

\section{Ex Vivo Experiments}

To obtain information regarding the effect of $\mathrm{A} \beta$ on PKC machinery, we studied the PKC activation, by evaluating the ratio between phospho-PCK and PKC $\alpha$, in CCh-stimulated rats. CCh-activated $\mathrm{PKC}$ as indicated by the increased ratio of phospho PKC versus $P K C \alpha$, when comparing the injected versus the controlateral (CL) side (see inset, Figure $4 \mathrm{~b}$ ). The CCh effect was fully prevented by pretreatment with the PKC inhibitor GF109203X (see inset, Figure $4 \mathrm{~b}$ ) or $\mathrm{A} \beta$, thus suggesting that the effect of $\mathrm{A} \beta$ on carbachol response was mediated by PKC activation (Figure $4 \mathrm{~b}$ ).

\section{In Vitro Experiments}

$\mathrm{CCh}$ and nicotine (Nic) were able to enhance significantly the basal release of $\left[{ }^{3} \mathrm{H}\right] \mathrm{DA}$ from accumbal nerve endings. The dose-response curves of $\mathrm{CCh}$ and Nic reported in 

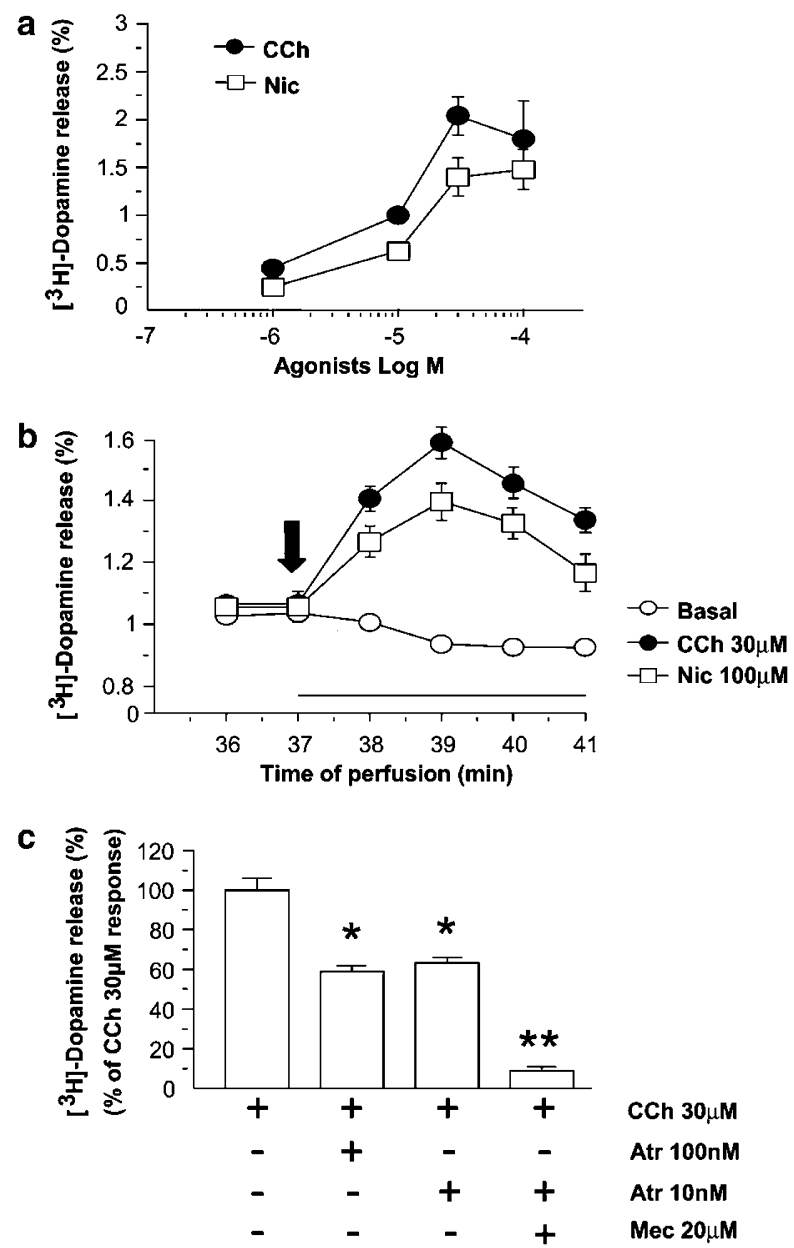

Figure 5 Characterization of carbachol (CCh) and nicotine (Nic) evoked $\left[{ }^{3} \mathrm{H}\right]$ dopamine (DA) release from rat accumbal synaptosomes. (a) Concentration-response curves of $\left[{ }^{3} \mathrm{H}\right] \mathrm{DA}$ overflow by $\mathrm{CCh}$ and Nic. (b) Time courses for CCh and Nic (black arrow indicates the time of agonists administration and black line indicates permanent stimulation). (c) Effect of a maximally effective CCh concentration on DA release and inhibition by atropine (Atr) and mecamylamine (Mec). Data are means \pm SEM of nine experiments run in triplicate. ${ }^{*} * P<0.0$ I; ${ }^{*} P<0.05$ vs $30 \mu \mathrm{M}$ CCh (two-tailed Student's t-test).

Figure $5 \mathrm{a}$ show that the maximum effect was reached at $30 \mu \mathrm{M}$ for $\mathrm{CCh}$ and at $100 \mu \mathrm{M}$ for $\mathrm{Nic}$ with an $\mathrm{EC}_{50}$ respectively of $6.76 \pm 2.01 \times 10^{-6}$ and $1.13 \pm 0.08 \times 10^{-5}$.

The time courses of $\left[{ }^{3} \mathrm{H}\right] \mathrm{DA}$ release evoked by $\mathrm{CCh}$ and Nic are illustrated in Figure 5b. The peak effect was observed both for $\mathrm{CCh}$ and Nic at min 39 of superfusion.

Figure $5 c$ shows that the release of $\left[{ }^{3} \mathrm{H}\right] \mathrm{DA}$ elicited by $30 \mu \mathrm{M}$ CCh was partially antagonized by atropine (Atr, 10 and $100 \mathrm{nM}$ ) and almost abolished by $10 \mathrm{nM}$ Atr plus $20 \mu \mathrm{M}$ of Mec.

The $\left[{ }^{3} \mathrm{H}\right] \mathrm{DA}$ release evoked by CCh $(30 \mu \mathrm{M})$ in accumbal isolated nerve endings was significantly reduced by $100 \mathrm{nM}$ $\mathrm{A} \beta$, while $10 \mathrm{nM} \mathrm{A} \beta$ was ineffective (Figure $6 \mathrm{a}$ ). The CChinduced release remaining after $\mathrm{A} \beta$ 1-40 was completely blocked by Mec. Also A $\beta$ 1-42 (100 nM) significantly reduced the DA release evoked by $\mathrm{CCh}$ to a similar extent.

To shed light on the selectivity of the effect of $\mathrm{A} \beta$ on the muscarinic and nicotinic receptors (nAChRs), we performed experiments in which the $\mathrm{KCl}$ evoked release of
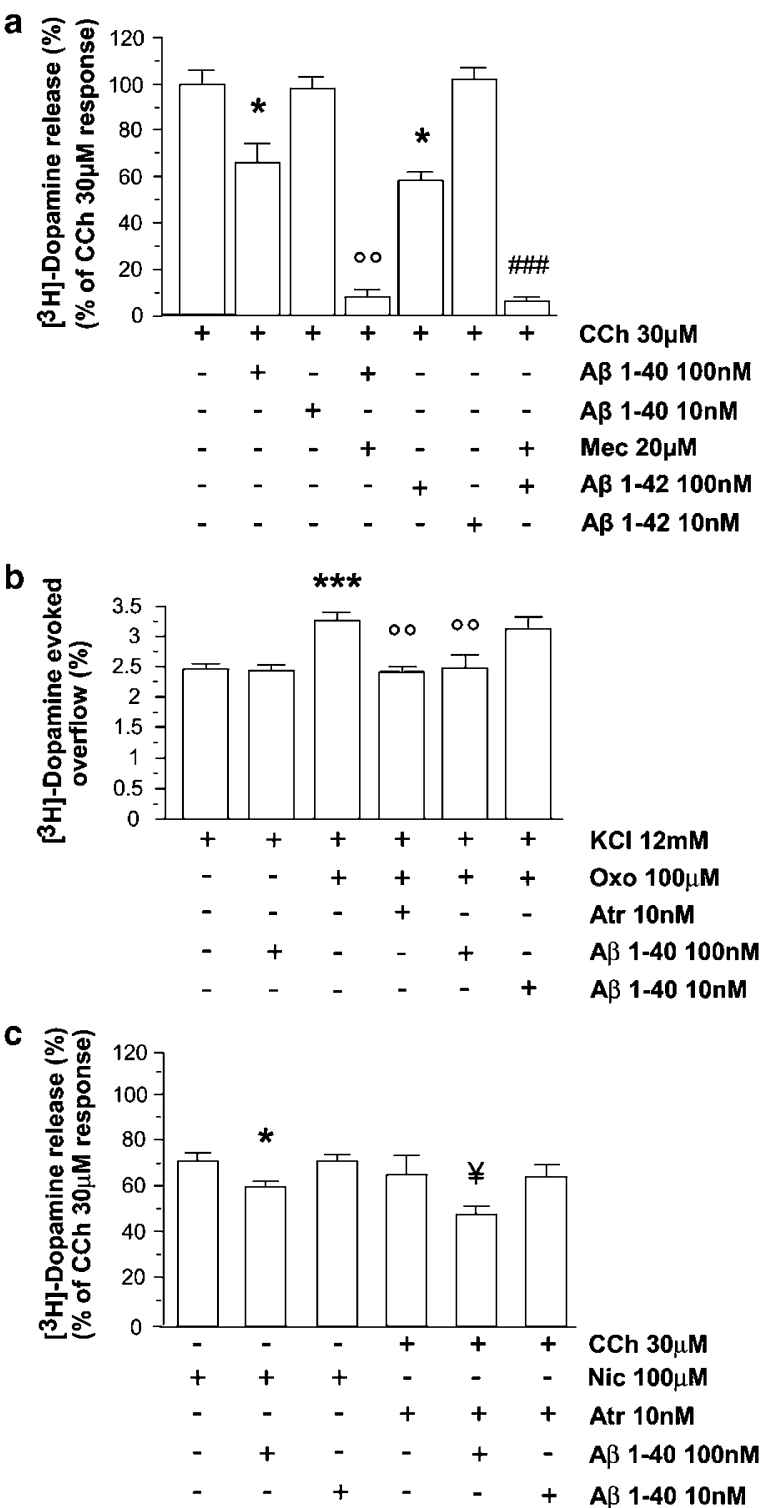

Figure 6 Effect of $\beta$-amyloid $(A \beta)$ on the carbachol (CCh) and nicotinestimulated $\left.{ }^{3} \mathrm{H}\right]$ dopamine (DA) release in accumbal synaptosomes. (a) Effect of $A \beta \quad--40$ and $A \beta \quad-42$ infusions on $\left.{ }^{3}{ }^{H} \mathrm{H}\right]-\mathrm{DA}$ release from accumbal synaptosomes. $A \beta \mid-40(100 \mathrm{nM})$ and $A \beta \mid-42(100 \mathrm{nM})$ are unable to modify basal release (data not shown). *P $<0.05$ vs $30 \mu \mathrm{M} C \mathrm{CC}$; ${ }^{\circ} \mathrm{P}<0.0 \mathrm{I}$ vs $30 \mu \mathrm{M} C \mathrm{CC}+100 \mathrm{nM} \mathrm{A} \beta \mathrm{I}-40$; ${ }^{\# \#} \mathrm{P}<0.00$ I vs $30 \mu \mathrm{M}$ CCh +100 nM A $\beta$ |-42 (two-tailed Student's t-test). (b) Effect of $A \beta \mid-40$ on $\left[{ }^{3} \mathrm{H}\right] \mathrm{DA}$ overflow evoked by $\mathrm{KCl} 12 \mathrm{mM}$ alone or in combination with oxotremorine (Oxo). **** $<<0.00$ I vs $12 \mathrm{mM} \mathrm{KCl} ;{ }^{\circ} \mathrm{P}<0.01$ vs $12 \mathrm{mM} \mathrm{KCl}$ $+100 \mu \mathrm{M}$ Oxo (two-tailed Student's t-test). (c) Nicotinic component of $\left[{ }^{3} \mathrm{H}\right] \mathrm{DA}$ release is partially affected by $A \beta \quad \mid-40$ infusion. ${ }^{*} P<0.05$ vs $100 \mu \mathrm{M}$ Nic; ${ }^{¥} \mathrm{P}<0.05$ vs $30 \mu \mathrm{M}$ CCh $+10 \mathrm{nM}$ Atr (two-tailed Student's t-test). Data are means \pm SEM of 6-10 experiments run in triplicate.

$\left[{ }^{3} \mathrm{H}\right] \mathrm{DA}$ was further enhanced by oxotremorine (Oxo) through the activation of muscarinic receptors as previously shown (Marchi et al, 1985).

Figure $6 \mathrm{~b}$ shows that $100 \mathrm{nM} \mathrm{A} \beta$, which did not modify the $\mathrm{KCl}$ evoked release of $\left[{ }^{3} \mathrm{H}\right] \mathrm{DA}$, completely counteracted the potentiating effect of $100 \mu \mathrm{M}$ Oxo which was also abolished by Atr. A $\beta$ (10 nM) was completely ineffective.

The effect of $\mathrm{A} \beta$ on the nicotinic stimulation of $\left[{ }^{3} \mathrm{H}\right] \mathrm{DA}$ release is reported in Figure 6c. 
a

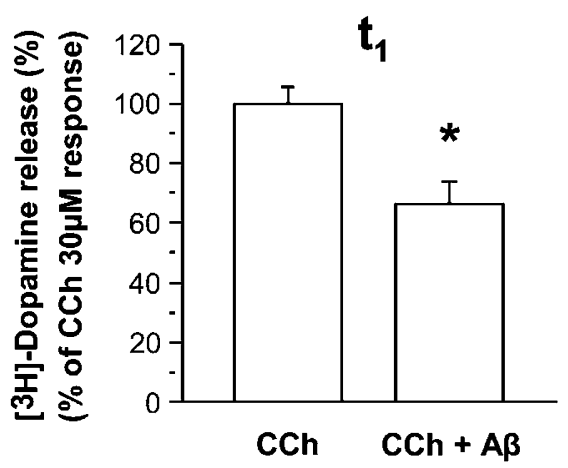

b

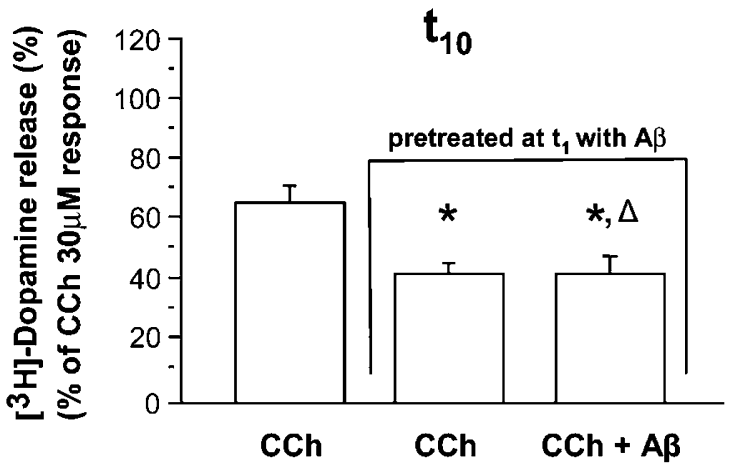

c

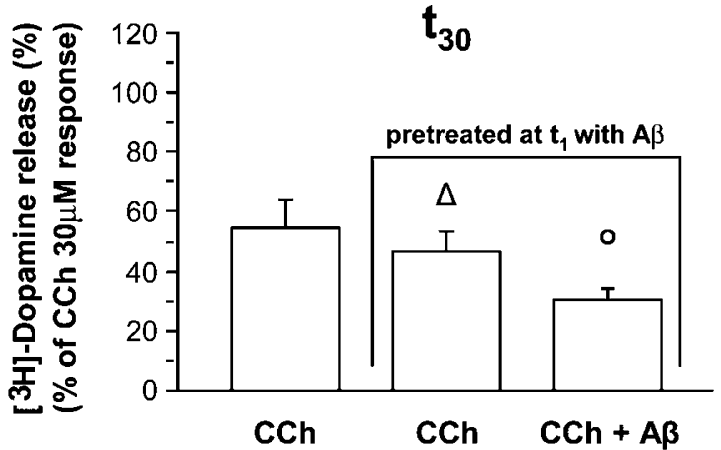

Figure 7 Effect of $\beta$-amyloid I-40 (A $\beta)$ on CCh-evoked DA release in nucleus accumbens synaptosomes following washing with physiological medium. (a) Effect of $A \beta$ on CCh induced DA release. $* P<0.05$ vs $30 \mu \mathrm{M}$ CCh (two-tailed Student's t-test). (b) Effect of $A \beta$ on CCh-induced DA release following 10 min continuous washing with physiological medium of A $\beta$ pretreated synaptosomes $* P<0.05$ vs $30 \mu \mathrm{M} C \mathrm{C}$, not pretreated with $A \beta ;{ }^{\Delta} P>0.05$ vs $C C h, A \beta$ pretreated. (c) Effect of $A \beta$ on CCh-induced DA release following 30 min continuous washing. ${ }^{\circ} P<0.05$ vs $30 \mu \mathrm{M} C \mathrm{CCh}, \mathrm{A} \beta$ pretreated; ${ }^{\Delta} P>0.05$ vs $C C h$, not pretreated with $A \beta$ (two-tailed Student's t-test). Data are means \pm SEM of 6-10 experiments run in triplicate.

The inhibitory effect of $100 \mathrm{nM} \mathrm{A} \beta$ on the nic evoked $\left[{ }^{3} \mathrm{H}\right] \mathrm{DA}$ release was modest and similar to that produced by $\mathrm{A} \beta$ on the $\left[{ }^{3} \mathrm{H}\right] \mathrm{DA}$ release evoked by $\mathrm{CCh}$ in presence of Atr.

Figure 7 shows the effect of $A \beta 1-40$ in control (panel a) and in $\mathrm{A} \beta$ 1-40 pretreated synaptosomes after 10 and 30 min washing with physiological medium (panel b and c, last two columns). Note that in each panel the control response to $\mathrm{CCh}$ is reported, which showed a timedependent decrease (at $t_{10}$ and $t_{30}$ compared to $t_{1}$ ). After 10 min washing the release of $\left[{ }^{3} \mathrm{H}\right] \mathrm{DA}$ elicited by $\mathrm{CCh}$ from nerve endings pretreated with $\mathrm{A} \beta$ was still inhibited. Moreover, further addition of $\mathrm{A} \beta$ at this time did not produce a further inhibitory effect (Figure $7 \mathrm{~b}$ ). However, after $30 \mathrm{~min}$ of continuous washing with normal medium the response of nerve endings to $\mathrm{CCh}$ recovered to the respective control level and the addition of $\mathrm{A} \beta$ to the perfusion medium produced again an inhibition of the CCh-evoked DA release (Figure 7c).

\section{DISCUSSION}

The results reported here show that acute administration of $\mathrm{A} \beta$ in vivo and in vitro impairs the ability of $\mathrm{CCh}$ to promote DA release from DA nerve terminals in rat nucleus accumbens. This observation extends previously published data (Itoh et al, 1996; $\mathrm{Li}$ and Smith, 1996), indicating that $\mathrm{A} \beta$ can affect neurotransmitter release in in vivo or in vitro conditions. In particular, our experiments demonstrate that cholinergic activation by $\mathrm{CCh}$ administration elicits a robust DA release from the shell of nucleus accumbens in freely moving adult rats. The CCh effect is mediated by the stimulation of cholinergic muscarinic receptors as indicated by the fact that the increase of DA release is inhibited by Atr and not by Mec. The activation of nicotinic receptors, by means of Epi administration, can also promote the release of DA in the nucleus accumbens, but the extent of the activation is roughly $1 / 3$ of that elicited by muscarinic receptor activation.

The results with isolated nerve terminals confirm and extend the in vivo results showing specifically that $\mathrm{CCh}$ and Nic can directly induce an increase in DA release by presynaptically activating both muscarinic and nicotinic receptors located on dopaminergic nerve terminals. These findings are also in agreement with previous results showing that both receptors are equally potent in stimulating DA release (Grilli et al, 2005; Raiteri et al, 1984; Summers et al, 1997). However, our results suggest a quantitatively predominant role of muscarinic receptors in the in vivo modulation of DA release by CCh. The effect of CCh through muscarinic receptors seems to involve a PKC transduction machinery downstream of the receptors, since it is prevented by the administration of the PKC inhibitor GF109203X. The effect of $\mathrm{A} \beta 1-40$ was persistent when continuously infusing the peptide. On the other hand, when the infusion was stopped and CCh-induced DA release evaluated 180 and 240 min after having stopped the infusion of $\mathrm{A} \beta$, the mean values appeared lower than those observed with $\mathrm{CCh}$ alone but the difference did not reach the statistical significance. It should be stressed that at $240 \mathrm{~min}$ the peptide had been almost completely cleared from the brain. In vitro the effect persisted for 10 but not $30 \mathrm{~min}$ after washing the peptide. All together, the results suggest that $\mathrm{A} \beta 1-40$ may give origin to molecular events inhibiting the CCh-induced DA release that may outlast for some time its presence, but are basically reversible. Alternatively, it is possible that the remaining effect is due to small amounts of the peptide tightly bound to the tissue and not cleared after washing. Notably, while the muscarinic receptor-activated DA release was completely counteracted by $1 \mu \mathrm{M} \mathrm{A} \beta$, the overflow of DA elicited by nicotinic receptors activation through Epi administration was conversely insensitive to $\mathrm{A} \beta$ infusion. Similarly, nicotinic stimulation of $\left[{ }^{3} \mathrm{H}\right] \mathrm{DA}$ release from isolated nerve endings was poorly affected. The small inhibitory effect observed with $\mathrm{A} \beta$ in vitro is consistent with a partial 
functional inhibition of $\alpha 4 \beta 2$ and $\alpha 7 \mathrm{nAChRs}$ by $\mathrm{A} \beta$, as observed previously (for a review see Liu and Wu, 2006). It has to be noted (Salminen et al, 2004; Quik and McIntosh, 2006) that $\alpha 7 \mathrm{nAChRs}$ do not seem to be involved in the modulation of DA release in this brain area. Therefore, the modest inhibitory effect we have observed in vitro could indeed be due to the multiple nAChRs subtypes, not only $\alpha 4 \beta 2$, which are present on DA accumbal nerve ending and are involved in the modulation of DA release.

The reason for the different sensitivity of nicotinic and muscarinic receptor-mediated DA outflow stimulation has not yet been fully elucidated but it is possible that $\mathrm{A} \beta$ infusion acutely impairs the PKC transduction machinery as has been suggested by Zhong et al (2003) in their study on the disruption by $\mathrm{A} \beta$ of the CCh modulation of GABAergic response in prefrontal cortex (PFC). This view is supported by our ex vivo data showing that $\mathrm{A} \beta$ affects the phospho PKC/PKC ratio. It should be stressed, however, that these data indicate that PKC may mediate the effect of $\mathrm{A} \beta 1-40$ but do not demonstrate it. The mechanism by which PKC inhibition may inhibit DA release may rely on the fact that this kinase phosphorylates presynaptic proteins correlated with neurotransmitter release such as GAP 43 as originally shown in rat hippocampus (Dekker et al, 1990) or acting through an increased calcium sensitivity of vesicle fusion as recently suggested by Lou et al (2005). The effect of $\mathrm{A} \beta$ on DA release is specific since it is not observed with the reverse peptide $\mathrm{A} \beta 40-1$. It is probably due to the passage through the dialysis fiber of soluble $\mathrm{A} \beta$ monomers or small molecular weight oligomers, since the cutoff size of the dialysis membrane is $40000 \mathrm{DA}$. On the other hand, immunocytochemical inspection indicated that under our experimental conditions, $\mathrm{A} \beta$ diffuses through the dialysis membrane to the tissue where it is found in proximity of the dialysis probe. No gross signs of neurodegeneration were observed within the area of amyloid diffusion as shown by Hoechst immunocytochemistry, and as expected within the time frame (from $40 \mathrm{~min}$ to few hours) using a low micromolar freshly prepared $\mathrm{A} \beta$ 1-40 solution. Notably, in our in vivo study, $\mathrm{A} \beta 1-42(10 \mu \mathrm{M})$ was devoid of the effects observed with $\mathrm{A} \beta$ 1-40 prompting us to use $\mathrm{A} \beta$ 1-40. However, it is possible that, due to its greater propensity to form aggregates, the adopted conditions were unfavorable for the administration of $A \beta 1-42$. Indeed when we perfused A $\beta$ 1-42 the amounts found in the nucleus accumbens were much lower than those observed following $\mathrm{A} \beta$ 1-40 perfusion. This observation is in agreement with the study by Sabella et al (2004), showing a greater propensity of A $\beta$ 1-42 to aggregate in large molecular weight oligomers. When performing in vitro experiments, exposing directly the synaptosomes to the peptides, this difference was not observed and $\mathrm{A} \beta 1-40$ and $\mathrm{A} \beta$ 1-42 had identical activities (Figure 6a). The choice of $\mathrm{A} \beta$ 1-40 was further supported by the observation that the 40 -amino-acid long peptide is the most abundant form (Kamenetz et al, 2003; Terai et al, 2001; Walsh and Selkoe, 2007): the concentration of secreted A $\beta$ $1-42$ is about $10 \%$ that of $\mathrm{A} \beta 1-40$ (Bitan et al, 2003). On the other hand, in other experimental conditions, $A \beta 1-40$ and A $\beta$ 1-42 may even have different biological actions (Zou et al, 2003) and the ratio of their production may be altered by the disease, at least in familial AD (Mayeux et al, 1999).
These data are in agreement with the emerging view that amyloid, with mechanisms still to be fully elucidated, may regulate synaptic responses (Kamenetz et al, 2003; Kokubo et al, 2005; Zhong et al, 2003). Moreover, the observation that $\mathrm{A} \beta$ in vivo can regulate the activity of cholinergic synapses in turn controlling DA release is intriguing for several reasons. First, if A $\beta$ 1-40, under conditions not leading to neurotoxicity, participates in the modulation of the cholinergic control of DA release, a disease associated with a disruption of $\mathrm{A} \beta$ production (either an increased production or an altered $\mathrm{A} \beta$ 1-40/1-42 ratio) may have functional consequences on the cholinergic regulation of other neurotransmitters before neurotoxicity is observed. In the case of the cholinergic control of DA in nucleus accumbens, these functional effects may involve alterations of adaptive capacities, selective attention or working memory and executive function.

We still do not know whether the effect of $\mathrm{A} \beta 1-40$ on DA release evoked by $\mathrm{CCh}$ is specific for nucleus accumbens or can be observed also in other brain areas and in the case of other neurotransmitters. The prediction would be that where the release of a transmitter is modulated by muscarinic cholinergic receptors $\mathrm{A} \beta$ can disrupt this regulation. In our hands preliminary studies performed on PFC using the described approach were unsuccessful due to sensitivity problems. On the other hand, Trabace et al (2007) using a transverse dialysis probe with a greater exposed surface was able to document an inhibitory action of $\mathrm{A} \beta$ intraventricular infusion on DA release also in PFC. This last observation is intriguing since this area plays a critical role in elaborating thoughts, behavior and working memory. Furthermore, dysfunctions of the dopaminergic system in PFC are considered to be major contributing factors to the pathophysiology of mental disease (Trabace et al, 2007).

From a clinical point of view, the data obtained suggest the possibility of dysfunctions involving neurotransmitters other than acetylcholine and alterations of cognitive functions not exclusively limited to memory, possibly preceding a neurodegeneration-related loss of function. In turn, this suggests the possibility of investigating by means of neuropsychological tests, functions other than memory in the prodromic phases of the disease and to explore new therapeutic strategies.

\section{ACKNOWLEDGEMENTS}

This work was supported by the contribution of grants from the Ministry of University and Research (MIUR, Grant no. 2005051707 to SG).

\section{DISCLOSURE}

None of the authors has conflict of interest.

\section{REFERENCES}

Arnsten AF, Li BM (2005). Neurobiology of executive functions: catecholamine influences on prefrontal cortical functions. Biol Psychiatry 57: 1377-1384.

Baudic S, Barba GD, Thibaudet MC, Smagghe A, Remy P, Traykov L (2006). Executive function deficits in early Alzheimer's 
disease and their relations with episodic memory. Arch Clin Neuropsychol 21: 15-21.

Bitan G, Kirkitadze MD, Lomakin A, Vollers SS, Benedek GB, Teplow DB (2003). Amyloid beta -protein (Abeta) assembly: abeta 40 and Abeta 42 oligomerize through distinct pathways. Proc Natl Acad Sci USA 100: 330-335.

Brilliant MJ, Elble RJ, Ghobrial M, Struble RG (1997). The distribution of amyloid beta protein deposition in the corpus striatum of patients with Alzheimer's disease. Neuropathol Appl Neurobiol 23: 322-325.

De Klippel N, Sarre S, Ebinger G, Michotte Y (1993). Effect of M1- and M2-muscarinic drugs on striatal dopamine release and metabolism: an in vivo microdialysis study comparing normal and 6-hydroxydopaminelesioned rats. Brain Res 630: 57-64.

Dekker LV, De Graan PN, Spierenburg H, De Wit M, Versteeg DH, Gispen WH (1990). Evidence for a relationship between B-50 (GAP-43) and $\left[{ }^{3} \mathrm{H}\right]$ noradrenaline release in rat brain synaptosomes. Eur J Pharmacol 188: 113-122.

Di Chiara G, Tanda G, Frau R, Carboni E (1993). On the preferential release of dopamine in the nucleus accumbens by amphetamine: further evidence obtained by vertically implanted concentric dialysis probes. Psychopharmacology 112: 398-402.

Germano C, Kinsella GJ (2005). Working memory and learning in early Alzheimer's disease. Neuropsychol Rev 15: 1-10.

Giorquieff MF, Le Floc'h ML, Glowinski J, Besson MJ (1977). Involvement of cholinergic presynaptic receptors of nicotinic and muscarinic types in the control of the spontaneous release of dopamine from striatal dopaminergic terminals in the rat. J Pharmacol Exp Ther 200: 535-544.

Govoni S, Bergamaschi S, Racchi M, Battaini F, Binetti G, Bianchetti A et al (1993). Cytosol protein kinase C downregulation in fibroblasts from Alzheimer's disease patients. Neurology 43: 2581-2586.

Grilli M, Parodi M, Raiteri M, Marchi M (2005). Chronic nicotine differentially affects the function of nicotinic receptor subtypes regulating neurotransmitter release. J Neurochem 93: 1353-1360.

Hof PR, Morrison JH (2004). The aging brain: morphomolecular senescence of cortical circuits. Trends Neurosci 27: 607-613.

Itoh A, Nitta A, Nadai M, Nishimura K, Hirose M, Hasegawa T et al (1996). Dysfunction of cholinergic and dopaminergic neuronal systems in $\beta$-Amyloid protein - infused rats. J Neurochem 66: 1113-1117.

Kamenetz F, Tomita T, Hsieh H, Seabrook G, Borchelt D, Iwatsubo $\mathrm{T}$ et al (2003). APP processing and synaptic function. Neuron 37: 925-937.

Kitamura M, Koshikawa N, Yoneshige N, Cools AR (1999). Behavioural and neurochemical effects of cholinergic and dopaminergic agonists administered into the accumbal core and shell in rats. Neuropharmacology 38: 1397-1407.

Kokubo H, Kayed R, Glabe CG, Yamaguchi H (2005). Soluble Abeta oligomers ultrastructurally localize to cell processes and might be related to synaptic dysfunction in Alzheimer's disease brain. Brain Res 1031: 222-228.

Lanni C, Mazzucchelli M, Porrello E, Govoni S, Racchi M (2004). Differential involvement of protein kinase $\mathrm{C}$ alpha and epsilon in the regulated secretion of soluble amyloid precursor protein. Eur J Biochem 271: 3068-3075.

Li M, Smith CP (1996). Beta-amyloid 1-40 inhibits electrically stimulated release of $\left[{ }^{3} \mathrm{H}\right]$ norepinephrine and enhances the internal calcium response to low potassium in rat cortex: prevention with a free radical scavenger. Brain Res Bull 39: 299-303.

Liu Q, Wu J (2006). Neuronal nicotinic acetylcholine receptors serve as sensitive targets that mediate $\beta$-amyloid neurotoxicity. Acta Pharmacologica Sinica 27: 1277-1286.

Lou X, Scheuss V, Schneggenburger R (2005). Allosteric modulation of the presynaptic $\mathrm{Ca}^{2+}$ sensor for vesicle fusion. Nature 435: 497-501.
Mann DM, Iwatsubo T (1996). Diffuse plaques in the cerebellum and corpus striatum in Down's syndrome contain amyloid beta protein (Abeta) only in the form of Abeta 42(43). Neurodegeneration 5: 115-120.

Marchi M, Paudice P, Bonanno G, Raiteri M (1985). Presynaptic muscarinic receptor activation enhances striatal dopamine release evoked by depolarization but not that induced by nondepolarizing stimuli. Neurochem Int 7: 137-141.

Mayeux R, Tang MX, Jacobs DM, Manly J, Bell K, Merchant C et al (1999). Plasma amyloid beta-peptide 1-42 and incipient Alzheimer's disease. Ann Neurol 46: 412-416.

Nieoullon A (2002). Dopamine and the regulation of cognition and attention. Prog Neurobiol 67: 53-83.

Nieoullon A, Coquerel A (2003). Dopamine: a key regulator to adapt action, emotion, motivation and cognition. Curr Opin Neurol 16(Suppl 2): S3-S9.

Paxinos G, Watson C (1998). The Rat Brain in Stereotaxic Coordinates. Academic Press: New York, London.

Quik M, McIntosh JM (2006). Striatal alpha6* nicotinic acetylcholine receptors: potential target for Parkinson's disease therapy. J Pharmacol Exp Ther 316: 481-489.

Raiteri M, Leardi R, Marchi M (1984). Heterogeneity of presynaptic muscarinic receptors regulating neurotransmitter release in the rat brain. J Pharmacol Exp Ther 228: 209-214.

Sabella S, Quaglia M, Lanni C, Racchi M, Govoni S, Caccialanza G et al (2004). Capillary electrophoresis studies on the aggregation process of $\beta$ amyloid 1-42 and 1-40 peptides. Electrophoresis 25: 3186-3194.

Salminen O, Murphy KL, MsIntosh JM, Drago J, Marks MJ, Collins AC et al (2004). Subunit composition and pharmacology of two classes of striatal presynaptic nicotinic acetylcholine receptors mediating dopamine release in mice. Mol Pharmacol 65: 1526-1535.

Suenaga T, Hirano A, Llena JF, Yen SH, Dickson DW (1990). Modified Bielschowsky stain and immunohistochemical studies on striatal plaques in Alzheimer's disease. 80: 280-286.

Summers KL, Kem WR, Giacobini E (1997). Nicotinic agonist modulation of neurotransmitter levels in the rat frontoparietal cortex. Jpn J Pharmacol 74: 139-146.

Terai K, Iwai A, Kawabata S, Tasaki Y, Watanabe T, Miyata K et al (2001). amyloid-deposits in transgenic mice expressing human Bamyloid precursor protein have the same characteristics as those in Alzheimer's disease. Neuroscience 104: 299-310.

Trabace L, Kendrick KM, Castrignanò S, Colaianna M, De Giorgi A, Schiavone $S$ et al (2007). Soluble A $\beta$ 1-42 reduces dopamine levels in rat prefrontal cortex: relationship to nitric oxide. Neuroscience, doi:10.1016/j.neuroscience.2007.04.056.

Walsh DM, Selkoe DJ (2007). A $\beta$ Oligomers - a decade of discovery. J Neurochem 101: 1172-1184.

Waltz JA, Knowlton BJ, Holyoak KJ, Boone KB, Back-Madruga C, McPherson S et al (2004). Relational integration and executive function in Alzheimer's disease. Neuropsychology 18: 296-305.

Xu M, Mizobe F, Yamamoto T, Kato T (1989). Differential effects of M1- and M2-muscarinic drugs on striatal dopamine release and metabolism in freely moving rats. Brain Res 495: 232-242.

Zhang W, Yamada M, Gomeza J, Basile AS, Wess J (2002). Multiple muscarinic acetylcholine receptor subtypes modulate striatal dopamine release, as studied with M1-M5 muscarinic receptor knock-out mice. J Neurosci 22: 6347-6352.

Zhong P, Gu Z, Wang X, Jiang H, Feng J, Yan Z (2003). Impaired modulation of GABAergic transmission by muscarinic receptors in a mouse transgenic model of Alzheimer's disease. J Biol Chem 278: 26888-26896.

Zou K, Kim D, Kakio A, Byun K, Gong JS, Kim J et al (2003). Amyloid beta-protein (Abeta)1-40 protects neurons from damage induced by Abeta1-42 in culture and in rat brain. J Neurochem 87: 609-619. 